\title{
The Activation of PI3K/AKT/mTOR Signaling Pathway in Response to Cabazitaxel Treatment in Metastatic Castration-Resistant Prostate Cancer Cells
}

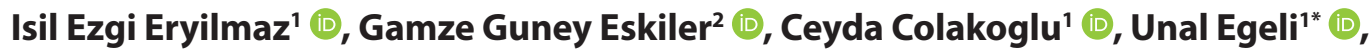 Gulsah Cecener ${ }^{1}$ (D)}

'Bursa Uludag University, Faculty of Medicine, Medical Biology Department, Bursa, Turkey

${ }^{2}$ Sakarya University, Faculty of Medicine, Medical Biology Department, Sakarya, Turkey

ORCID IDs of the authors: I.E.E. 0000-0002-3316-316X; G.G.E. 0000-0002-2088-9914; C.C. 0000-0002-7471-5071;

U.E. 0000-0001-7904-883X; G.C. 0000-0002-3820-424X

Please cite this article as: Eryilmaz IE, Guney Eskiler G, Colakoglu C, Egeli U, Cecener G. The Activation of PI3K/AKT/mTOR Signaling Pathway in Response to Cabazitaxel Treatment in Metastatic Castration-Resistant Prostate Cancer Cells. Eur J Biol 2021; 80(2): 138-144. DOI: 10.26650/EurJBiol.2021.1018938

\section{ABSTRACT}

Objective: Despite advances in treatment approaches, metastatic castration-resistant prostate cancer (mCRPC) remains a clinical challenge to treat. Cabazitaxel (Cab), a third-line chemotherapy option for mCRPC, exhibits limited efficiency due to the activation of different signaling pathways associated with drug resistance. The PI3K/AKT/mTOR activation has led to $\mathrm{mCRPC}$ progression, and long-term acquired Cab resistance. However, we aimed to assess the association of apoptotic efficiency of Cab with the PI3K/AKT/mTOR activation in MCRPC cells in the present study.

Materials and Methods: Cell viability, cell death, morphological analysis, PI3K/AKT/mTOR pathway activation by PI3K/MAPK dual activation assay, mRNA and miRNA expression analysis and immunofluorescence staining were performed in the Cabtreated PC3 cells.

Results: Cab caused a significant reduction in PC3 cell viability and triggered apoptotic death at 1 and $5 \mathrm{nM}$ for $72 \mathrm{~h}$. Cab significantly induced PI3K/AKT/mTOR activation, and increased mRNA and activated protein levels of AKT and mTOR in PC3 cells, despite its increased apoptotic effect. Furthermore, the expressions of miR-205 and miR-579, the PI3K/AKT/mTORtargeted miRNAs, were upregulated after Cab treatment. Our findings have shown that the Cab treatment activated PI3K/ AKT/mTOR pathway is associated with its apoptotic effect in mCRPC cells.

Conclusion: Although further studies are required to investigate the molecular mechanisms accompanying the Cab response in detail, the PI3K/AKT/mTOR activation, as an alteration related to the apoptotic effect of the drug, may play a role in Cab resistance in mCRPC cells, suggesting that combined therapy with PI3K/AKT/mTOR inhibitors may improve the Cab therapeutic efficiency.

Keywords: Cabazitaxel, Castration-resistant Prostate Cancer, AKT, mTOR, miRNAs

\section{INTRODUCTION}

Prostate cancer ( $\mathrm{PCa})$, the second most common solid tumor, is the fifth leading cause of cancer-related deaths in men (1). The recurrent form of the disease, castration-resistant prostate cancer (CRPC), frequently occurs after castration by surgery (orchiectomy) or chemically, with androgen deprivation therapy (ADT), which is the first-line treatment option in advanced PCa (2). Although there is a wide range of treatment options, including next-generation antiandrogens, autologous immunotherapy and internal radiotherapy for metastatic CRPC (mCRPC), chemotherapy with microtubule-targeting drugs, Paclitaxel (Pac) or Docetaxel 
(Doc), is used as a standard first-line option (3). One class of these agents that is only approved for the patients with ADTand Doc-resistant $\mathrm{MCRPC}$ is also the newer one, Cabazitaxel (Cab) (4). Despite these advances in MCRPC treatment over the past decade, long-term survival rates remain low, and there are no effective treatment options for MCRPC (5-8).

One of the molecular mechanisms, the activation of phosphatidylinositol-3-kinase $(\mathrm{PI} 3 \mathrm{~K}) /$ serine-threonine protein kinase $\mathrm{B}$ (AKT)/mammalian target of rapamycin (mTOR) pathway, has been strongly implicated in MCRPC progression and the acquired resistance to both conventional and targeted anticancer drugs (9-11). Liu et al. (2015) also indicate that PI3K/AKT/ mTOR and mitogen-activated protein kinase (MAPK) signaling pathways play a role in the development of Pac resistance in mCRPC cells (12). Although Cab has a different chemical structure containing extra methyl groups compared to Pac and Doc, which enables it to be more effective in Doc-resistant MCRPC (13), MCRPC patients eventually show clinical resistance, and the underlying mechanism of Cab-resistance is poorly understood. A recent study regarding in vitro Cab resistance mechanisms has shown that Cab-resistant MCRPC cells exhibit altered expression in gene clusters of mitotic cells and nuclear division. Additionally, Cab-resistant cells (DU145CR and PC3CR) exhibit a different PI3K/AKT/mTOR and MAPK activity (14). However, these studies have focused on the role of signaling pathways in Doc-, Pac- and Cab-resistant PCa cells. Thus, the activation of these pathways in response to Cab treatment remains unclear at the genetic and epigenetic levels. The relationship between the apoptotic efficacy of Cab and the Cab-targeted signaling pathways needs further investigation in mCRPC cells.

In the present study, we report the relationship between the apoptotic efficacy of Cab and the PI3K/AKT/mTOR activation in PC3 mCRPC cells through the determination of Akt and mTOR gene expression, activated protein levels, and associated miRNAs' (miR-205-3p, miR-340-5p, miR-579-3p, and miR-429) levels in the Cab-treated cells.

\section{MATERIALS AND METHODS}

\section{Cell Line and Culture Conditions}

The mCRPC cell line PC3 (ATCC ${ }^{\circledR}$ CRL-1435 ${ }^{\mathrm{TM}}$ ) was purchased from the American Type Culture Collection (ATCC) and cultured at $37^{\circ} \mathrm{C}$ and $5 \% \mathrm{CO}_{2}$ in a humid incubator (Panasonic, Japan). The Roswell Park Memorial Institute (RPMI)-1640 medium w/ sodium pyruvate and L-glutamine (Thermo Fisher Scientific, USA) supplemented with $10 \%$ fetal bovine serum (FBS, Thermo Fisher Scientific, USA), and $1 \%$ antibiotic-antimycotic solution (Wisent Bio Products, USA) was used as a growth medium and changed every 2 days. Cells were passaged with a Trypsin-EDTA $0.25 \%$ solution (Thermo Fisher Scientific, USA) as needed.

\section{Drug Treatment}

Cab (Catalog No: S3022) was purchased from Selleck Chemicals (Houston, TX) in a lyophilized powder form. The drug was prepared in dimethyl-sulphoxide (DMSO) to obtain a $5 \mathrm{mM}$ stock solution as indicated in the datasheet and stored at $-80^{\circ} \mathrm{C}$. An intermediate solution of $100 \mathrm{nM}$ was freshly diluted with a growth medium just before the experiments. The Cab doses were applied directly to the cultured cells on the plates. The amount of DMSO (Sigma-Aldrich, Germany) applied to cells was always kept below the toxic concentration $[<0.01 \%(\mathrm{v} / \mathrm{v})]$.

\section{Cell Viability}

The seeded cells, into 96 -well plates at a density of $2 \times 10^{4} /$ well, were incubated for attachment. Two concentrations of Cab, 1 and $5 \mathrm{nM}$, were exposed to the cells for $72 \mathrm{~h}$. After $10 \mu \mathrm{lWST}$ 1 reagent (BioVision, San Francisco, CA) was applied to each well, the cells were incubated until they metabolized the dye in a growth atmosphere. Relative cell viability was detected by obtaining absorbances for color intensity at $450 \mathrm{~nm}$ in a TriStar ${ }^{2}$ S LB 942 microplate reader (Berthold Technologies, Germany). Each treatment included three replicates for statistical data analysis.

\section{Apoptotic and Morphological Evaluation}

For determining the apoptotic effect of Cab, the cells $\left(5 \times 10^{5} \mathrm{cells} /\right.$ well) were seeded into 6-well plates and the drug treatment at 1 and $5 \mathrm{nM}$ was applied for $72 \mathrm{~h}$. After the indicated time, the cell staining was performed with a Muse Annexin V \& Dead Cell Kit (Merck Millipore, Germany) reagent for $30 \mathrm{~min}$ in the dark. Then, apoptotic cells were analyzed in three replicates in a Muse Cell Analyzer (Merck Millipore, Germany). For morphological assessment, the cells were stained with acridine orange dye after the fixation step with a $4 \%$ paraformaldehyde (PFA) solution (Sigma-Aldrich, Germany). Morphological changes in Cab-treated cells were observed under a cell imaging system (Thermo Fisher Scientific, Waltham, MA, USA).

\section{PI3K/MAPK Dual Activation Assay}

Activation of PI3K/MAPK pathways was examined simultaneously in the Cab-treated cells using a Muse PI3K/MAPK Dual Pathway Activation Kit that included two antibodies, a phospho-specific AKT (Ser473) and a phospho-specific ERK1/2 (Thr202/Tyr204, Thr185/Tyr187). Briefly, the cells were cultured in 6-well plates at an appropriate density and treated with 1 and $5 \mathrm{nM}$ Cab for $72 \mathrm{~h}$. After, the drug administration, fixation and permeabilization steps were performed according to the manufacturer's instructions. The staining was carried out with an antibody cocktail solution for 30 min and kept in the dark. Then, the pathway examination was obtained in triplicate in a Muse Cell Analyzer (Merck Millipore, Germany).

\section{Gene and miRNA Expression}

After treatment with 1 and $5 \mathrm{nM}$ Cab for $72 \mathrm{~h}$, total RNA samples and miRNAs were separately isolated from PC3 cells with a Total RNA I kit (Omega Bio-Tek Inc, Norcross, GA) and NucleoSpin miRNA Small RNA isolation kit (Macherey-Nagel, Germany), respectively. All RNA samples were checked for $A_{260} / A_{280}$ value and quantity with a spectrophotometer (Beckman Coulter, Inc., Fullerton, CA, USA). The reverse-transcription step was performed using a High-Capacity cDNA Reverse Transcription Kit (Applied Biosystems, Foster City, CA) and a miScript II RT Kit (Qiagen, Hilden, Germany). Then, RT-qPCR was done in an amplification 
mix containing miScript SYBR Green PCR Kit (Qiagen, Hilden, Germany) for miScript Primer Assays (Qiagen, Hilden, Germany) and TaqMan Gene Expression Master Mix for mRNAs (Hs00178289_ m1 AKT and Hs00234508_m1 mTOR) in a StepOnePlus Real-Time PCR System (Applied Biosystems, Foster City, CA). The miRNAs used in the study with their catalog numbers were miR-205$3 p$ (MS00016793), miR-340-5p (MS00031759), miR-579-3p (MS00007805) and miR-429 (MS00004193). In this way, relative gene and miRNA expression levels were determined in Cab-treated cells. As internal controls, Hs_RNU6-2_11 (MS00033740) and Actin beta (Hs01060665_g1 ACTB) were used for normalization. All expression analysis was performed in triplicate.

\section{Immunofluorescence Staining for Phosphorylated AKT and mTOR}

To visualize the subcellular localization of phosphorylated AKT and mTOR proteins, the Cab-treated PC3 cells were fixed with $4 \%$ PFA and blocked with 5\% normal goat serum. Then, the cells were incubated with primary antibodies (Santa Cruz Biotechnology, Germany), mouse p-AKT1/2/3 (sc-514021), and mouse p-mTOR (sc-293133). Subsequently, the cells were treated with goat anti-mouse Alexa Fluor 488 seconder antibody (Abcam,
Cambridge, UK). DAPI (Sigma Aldrich, St. Louis, Missouri, USA) staining was performed for nuclear visualization. Finally, the cells were examined under a cell imaging system (Thermo Fisher Scientific, Waltham, MA, USA).

\section{Statistical Analysis}

The GraphPad Prism 6.0 software (La Jolla, CA, USA) was used for statistics. The results were presented as the mean \pm standard deviation (SD). The significance of differences between the groups was assessed using an analysis of variance (ANOVA) with a Post-hoc test. Relative expressions of indicated genes and miRNAs were evaluated by using the $2^{\wedge}{ }^{-}(\Delta \Delta C t)$ method in a web-based tool at https://geneglobe.qiagen.com/us/analyze/. In all analyses, a p-value less than 0.05 was considered statistically significant.

\section{RESULTS}

\section{Cytotoxic and Apoptotic Effect of Cab on PC3 Cells}

Firstly, we evaluated the effective Cab concentrations inducing apoptosis in PC3 mCRPC cells. No significant cytotoxic effect was detected for 24 and $48 \mathrm{~h}$. However, as shown in Figure $1 \mathrm{~A}$, the 1

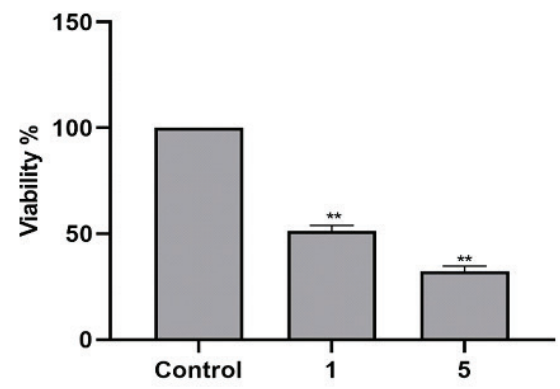

A

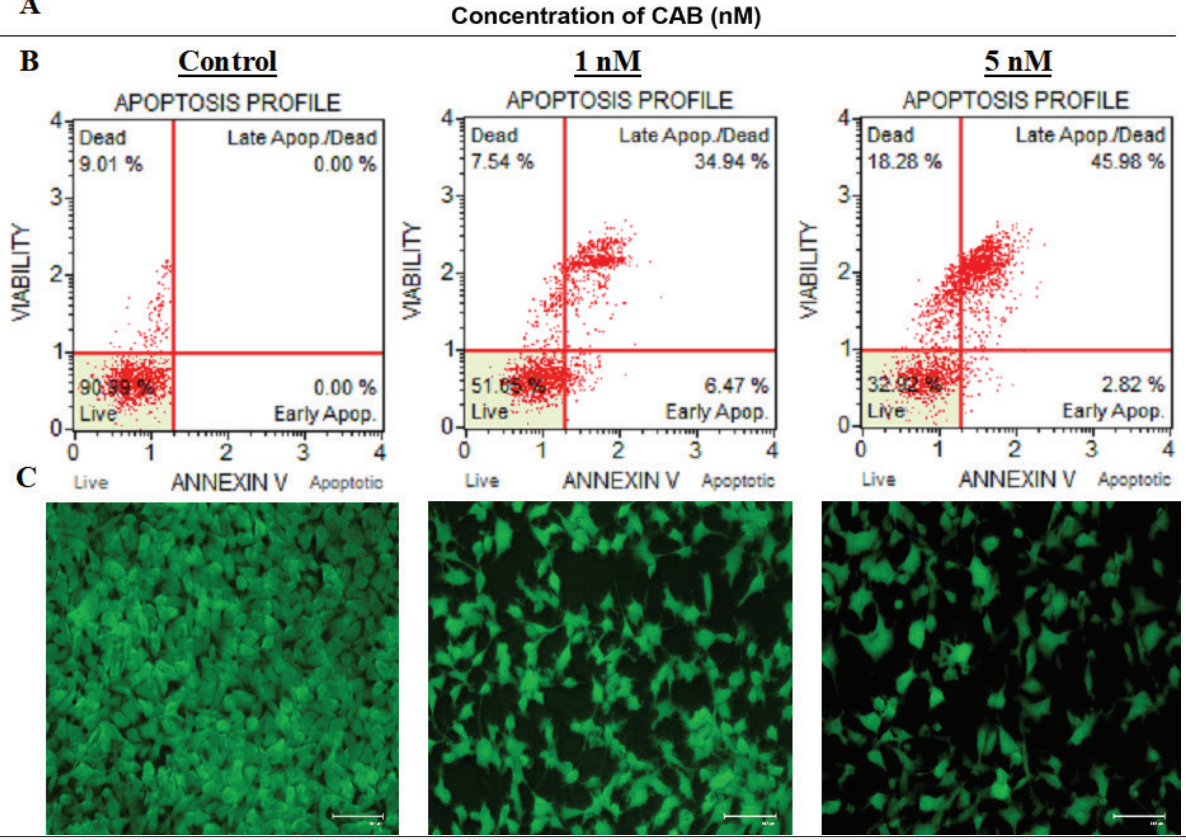

Concentration of CAB (nM)

Figure 1. (A) Cytotoxic and (B) apoptotic effects of 1 and $5 \mathrm{nM}$ Cabazitaxel treatment for $72 \mathrm{~h}$ in PC3 metastatic castration-resistant prostate cancer cells, ${ }^{* *} p<0.01$ (C) Morphological changes of the cells treated with 1 and $5 \mathrm{nM}$ Cabazitaxel for $72 \mathrm{~h}$, respectively at $100 \mu \mathrm{m}$ scale. 
and $5 \mathrm{nM}$ Cab treatment significantly decreased the cell viability to $51.2 \pm 2.7 \%$ and $32.3 \pm 2.3 \%$ for $72 \mathrm{~h}$, respectively $(p<0.01)$. The $\mathrm{IC}_{50}$ value of Cab was calculated as $1.25 \mathrm{nM}$ for PC3 cells at $72 \mathrm{~h}$. When the apoptotic effect of Cab was evaluated, the total apoptotic cells were found to increase by $41.4 \%$ and $48.8 \%$ after the 1 and $5 \mathrm{nM} \mathrm{Cab}$ treatment, respectively (Figure 1B). Additionally, morphological changes regarding apoptotic cell death were observed in the Cab-treated cells. Disappeared cytoplasmic extension, cell disassembly, and bleb formation were more prominent in the $5 \mathrm{nM}$ Cab-treated group, as shown in Figure 1C.

\section{The Activation of MAPK/PI3K Pathways Upon Treatment with Cab}

We also examined the alterations in dual MAPK/PI3K pathway activation in response to apoptotic effect in the 1 and $5 \mathrm{nM}$ Cab treatments in PC3 cells for $72 \mathrm{~h}$. As represented in Figure 2A, our findings revealed that ERK activation was not affected by any of the Cab treatments. However, the percentage of AKT activated cells significantly increased from $27.16 \pm 0.05 \%$ to $59.9 \pm 0.07 \%$ and $62.01 \pm 0.33 \%$ in the 1 and $5 \mathrm{nM} \mathrm{Cab}$-treated groups, respectively $(p<0.01)$. The negative cell population percentage decrease was also consistent with the increase in the AKT-activated cells (Figure 2B). Thus, we showed that the PI3K/AKT/mTOR pathway, rather than MAPK, was activated in PC3 cells despite the apoptotic effect of Cab.

\section{The Effect of Cab on the Expression Levels of AKT and mTOR} Cab treatments caused a significant increase in the mRNA levels of $A K T$ and $m T O R$ compared with the untreated control group (Figure 3A). The $1 \mathrm{nM}$ Cab treatment upregulated the $A K T$ level
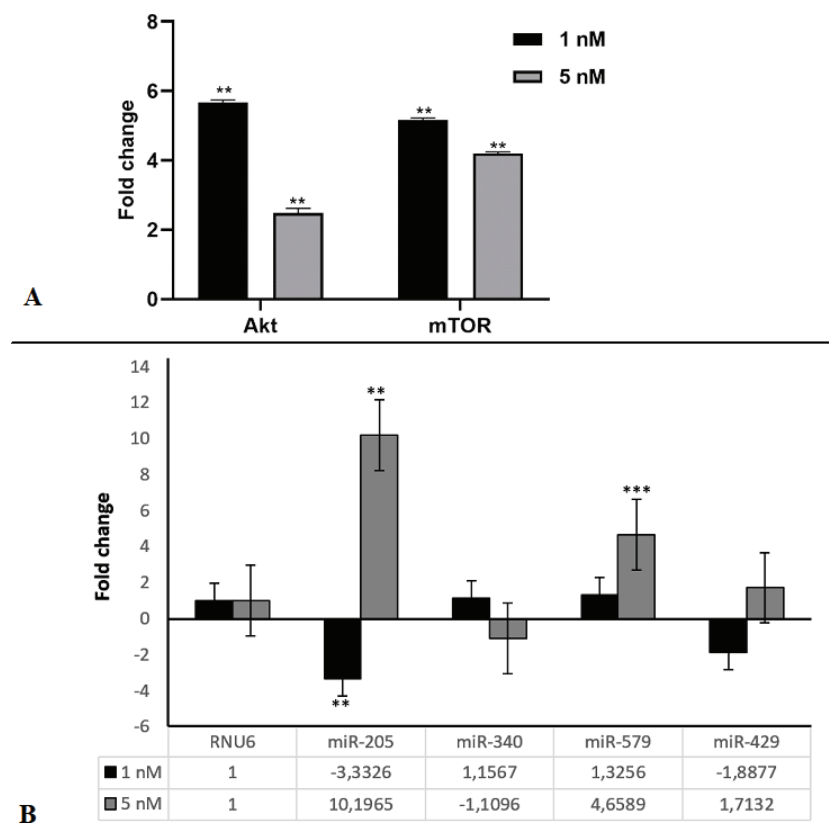

Figure 3. The relative fold changes in the RNA expression level of (A) Serine/threonine protein kinase B (Akt) and mammalian target of rapamycin (mTOR) (B) Phosphatidylinositol-3-kinase $(\mathrm{PI} 3 \mathrm{~K}) /$ serine-threonine protein kinase $\mathrm{B}(\mathrm{AKT}) /$ mammalian target of rapamycin (mTOR) pathway targeting microRNAs (miRNAs) after Cabazitaxel treatment with 1 and $5 \mathrm{nM}$ for $72 \mathrm{~h}$ in PC3 cells. ${ }^{* *} p<0.01,{ }^{* * *} p<0.001$.

A
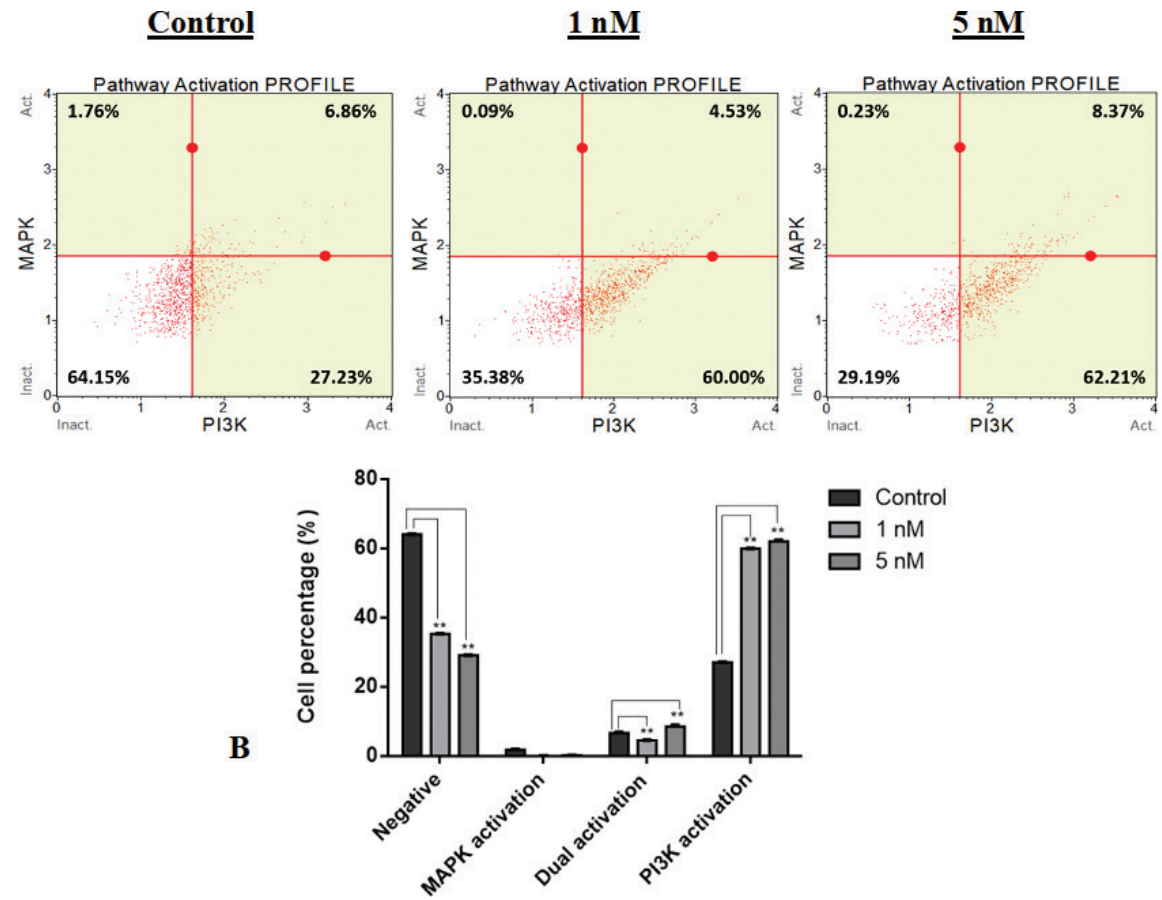

Figure 2. The results of mitogen-activated protein kinase (MAPK)/phosphatidylinositol-3-kinase (PI3K) activation in Cabazitaxel-treated PC3 cells. (A) Histograms of PI3K/MAPK dual pathway activation assay. (B) Statistical comparison of the MAPK/PI3K activated cell populations after 1 and $5 \mathrm{nM}$ Cabazitaxel treatment for $72 \mathrm{~h}$ compared to the untreated control group, ${ }^{* *} p<0.01$. 
by 5.67 -fold $(p<0.01)$. A noticeable increase $(5.17$-fold, $p<0.01$ ) was also detected in mTOR expression for the $1 \mathrm{nM}$ Cab-treated cells. Additionally, a significant upregulation of the indicated genes was detected in the $5 \mathrm{nM}$ treatment groups, as shown in Figure 3A. However, higher expression levels of AKT and mTOR were observed in the $1 \mathrm{nM}$ treatment group.

\section{The Effect of Cab on the Expression Levels of miRNAs}

Through a web-based tool, DIANA-miRPath, we selected four miRNAs that target the PI3K/AKT/mTOR signaling (miR-205$3 p$, miR-340-5p, miR-579-3p, and miR-429), and showed that neither miR-340 nor miR-429 levels changed after Cab treatment. However, the expression level of miR-205 was significantly down-regulated 3.33-fold $(p<0.01)$ after the $1 \mathrm{nM} \mathrm{Cab}$ treatment. However, the expression levels of miR-205 and miR579 were significantly upregulated $10.19-(p<0.01)$ and 4.65$(p<0.001)$ folds in the $5 \mathrm{nM}$ Cab-treated group, respectively (Figure 3B).
The Effect of Cab on the Subcellular Localization of Phosphorylated AKT and mTOR

Cab treatment changed the subcellular localization of $\mathrm{p}$-AKT and $\mathrm{p}$-mTOR, as shown in Figure 4. The cytoplasmic expression of the activated form of AKT, p-AKT, increased after the 1 and 5 nM Cab treatments for $72 \mathrm{~h}$, compared with the levels in the untreated cells (Figure 4A). Moreover, in connection with the activation of $\mathrm{p}-\mathrm{AKT}$, a higher nuclear and cytoplasmic expression of p-mTOR was visualized in the Cab-treated cells (Figure 4B). These results were consistent with the AKT/mTOR activation in the Cab-treated PC3 cells, as shown in Figure 2.

\section{DISCUSSION}

Our study determined that Cab induced the PI3K/AKT/mTOR signaling activation in PC3 MCRPC cells despite its significant apoptotic effect. The findings showed that Cab treatment led to a significant increase in AKT activation and mRNA level of AKT and $m T O R$. These findings were supported by immunofluores-

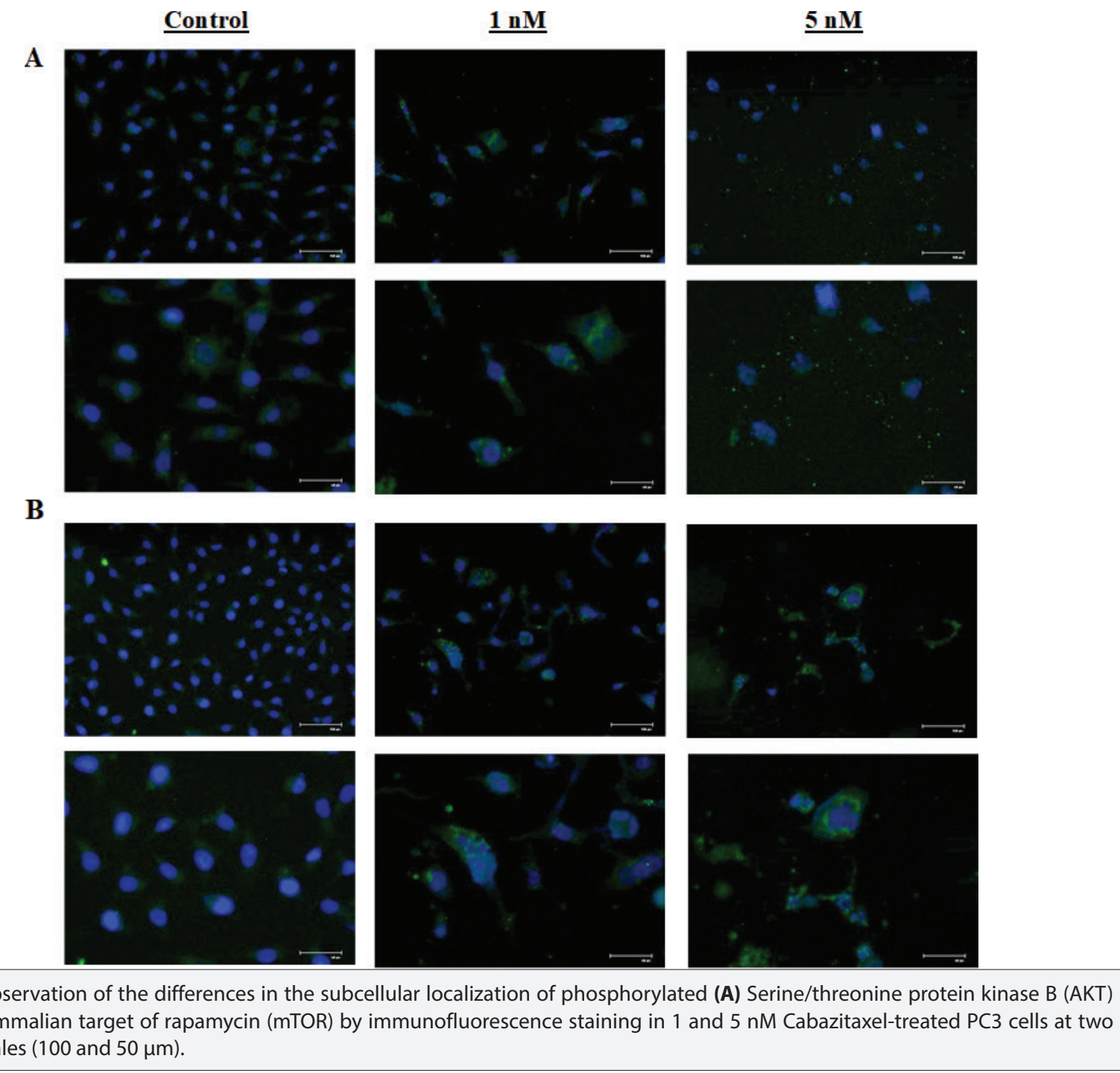

Figure 4. Observation of the differences in the subcellular localization of phosphorylated (A) Serine/threonine protein kinase B (AKT) and (B) Mammalian target of rapamycin (mTOR) by immunofluorescence staining in 1 and 5 nM Cabazitaxel-treated PC3 cells at two different scales (100 and $50 \mu \mathrm{m})$. 
cence staining of $\mathrm{p}$-AKT and p-mTOR protein levels. Additionally, the PI3K/AKT/mTOR activation was mediated by the upregulation of miR-205 and miR-579 in the Cab-treated PC3 cells.

Metastatic CRPC exhibits a poor prognosis due to decreased therapy response and drug resistance (15). Microtubule-targeting drugs are used as first-line options for MCRPC patients who have progressed after ADT, surgical or medical castration $(16,17)$. Cab, the new generation taxane, has been more active due to its improved structure than the other taxane-based chemotherapeutics $(7,13,18,19)$. Thus, it has been approved for mCRPC patients progressing after Doc treatment. Although Cab is a promising alternative, $\mathrm{MCRPC}$ remains a significant therapeutic challenge $(7,8,14,20)$.

$\mathrm{PI}$ IK/AKT/mTOR is one of the major oncogenic pathways for PCa (21). The phosphorylated AKT (p-AKT) is reported to be upregulated in advanced $\mathrm{PCa}$, directly linked to androgen receptor signaling, and contributes to CRPC progression (22-24). Moreover, recent reports have also indicated that the activation of PI3K/AKT/mTOR might be one of the resistance mechanisms after prolonged treatment, approximately two years, with taxane-based chemotherapeutics $(12,14,15)$. However, the alterations in this pathway accompanied by the apoptotic effect of Cab in mCRPC cells have not been investigated yet.

Herein, we first investigated the role of the PI3K/AKT/mTOR signaling pathway in the response of Cab in MCRPC cells. Our results showed that Cab significantly triggered late apoptosis in the treated cells for $72 \mathrm{~h}$. Interestingly, the Cab-mediated PI3K/AKT activation increased with the apoptotic effect of the drug. In the $5 \mathrm{nM}$ Cab-treated cells, apoptosis and PI3K/AKT activation were more prominent than in the $1 \mathrm{nM}$ treatment group. Cab treatment also resulted in the upregulation of AKT and mTOR at both mRNA and protein levels in PC3 cells at 72 h. These results suggest that, despite its apoptotic effect, Cab plays a role in the upregulation of the PI3K/AKT, which contributes to the survival and progression of PCa cells, as contributing to a previous study (12). Although the findings point to the role of $\mathrm{PI3K} / \mathrm{AKT} / \mathrm{mTOR}$ signaling in the Cab therapy response, the underlying molecular mechanisms of in vitro Cab-induced PI3K/ AKT/mTOR signaling need further investigation.

Moreover, Cab significantly altered the expression levels of miR205 and miR-579. A decreased level of miR-205 as an up-regulator of PI3K/AKT signaling has been associated with the worse clinical outcome in PCa patients $(25,26)$. Besides, miR-579 has been reported to be related to PCa recurrence (27). However, in glioblastomas, miR-579 has also been shown to directly target the 3'UTR of mTOR, exhibiting a tumor-suppressive effect (28). We found that, as compatible with the AKT activation, 1 nM Cab significantly down-regulated miR-205. However, 5 nM Cab caused a significant upregulation of miR-205 and miR-579 levels. Thus, the alterations of miR-205 and miR-579 could be mediated by Cab-induced PI3K/AKT activation. The Cab also increased the cytoplasmic and nuclear expression of $\mathrm{p}-\mathrm{AKT}$ and p-mTOR in PC3 cells. Besides being a cytoplasmic kinase, the active form of mTOR is also found in the nucleus of many cancer cells (29). The nuclear-localized mTOR involves transcription of rDNA and tRNA genes with RNA polymerase I and III, which contribute to cell growth, protein synthesis, and proliferation $(30,31)$. Therefore, we concluded that the activated p-AKT and p-mTOR might contribute to the survival of PC3 cells, which are not undergoing apoptotic death after $72 \mathrm{~h}$ Cab treatment. However, further investigations are required to identify the relationship between Cab efficacy and PI3K/AKT/mTOR pathway activation and related target genes or transcription factors, including GSK3 $\beta$ and FOXO1.

\section{CONCLUSION}

Consequently, Cab treatment induced apoptotic cell death in PC3 mCRPC cells. However, Cab simultaneously activated the $\mathrm{PI3K} / \mathrm{AKT} / \mathrm{mTOR}$ signaling pathway in the cells. Based on the results, we suggest that the PI3K/AKT/mTOR signaling pathway alterations may represent an early resistance mechanism for Cab treatment in MCRPC cells. Thus, further in vitro and in vivo studies should focus on combined or subsequent therapy with Cab and PI3K/AKT/mTOR inhibitors in mCRPC cells and PI3K/ AKT/mTOR pathway-associated genes or transcription factors.

Informed Consent: Written consent was obtained from the participants.

Peer Review: Externally peer-reviewed.

Author Contributions: Conception/Design of Study- I.E.E., G.G.E., U.E.; Data Acquisition- I.E.E., G.G.E.; Data Analysis/Interpretation- I.E.E., G.G.E., U.E., C.C.; Drafting Manuscript- I.E.E., G.G.E., C.C.; Critical Revision of Manuscript- U.E., G.C.; Final Approval and Accountability- I.E.E., G.G.E., U.E., C.C., G.C.

Conflict of Interest: Authors declared no conflict of interest.

Financial Disclosure: This study was supported by a grant from the Scientific Research Projects Foundation of Bursa Uludag University, Bursa, Turkey [Project No. BUAP(T)-2015/4].

\section{REFERENCES}

1. Ferlay J, Ervik M, Lam F, Colombet M, Mery L, Piñeros M, et al. Global cancer observatory: cancer today 2020. Lyon, France: International Agency for Research on Cancer 2018. https://gco.iarc.fr/ today. Accessed May 27, 2021.

2. Huang $Y$, Jiang $X$, Liang $X$, Jiang $G$. Molecular and cellular mechanisms of castration resistant prostate cancer. Oncol Lett 2018; 15 : 6063-76.

3. Lowrance WT, Roth BJ, Kirkby E, Murad MH, Cookson MS. Castration-Resistant Prostate Cancer: AUA Guideline Amendment 2015. J Urol 2015; 195: 1444-52.

4. Abidi A. Cabazitaxel: A novel taxane for metastatic castration-resistant prostate cancer-current implications and future prospects. J Pharmacol Pharmacother 2013; 4: 230-7.

5. de Bono JS, Oudard S, Ozguroglu M, Hansen S, Machiels JP, Kocak I, et al. Prednisone plus cabazitaxel or mitoxantrone for metastatic castration-resistant prostate cancer progressing after docetaxel treatment: a randomised open-label trial. Lancet 2010; 376: 1147-54. 
6. Nuhn P, De Bono JS, Fizazi K, Freedland SJ, Grilli M, Kantoff PW, et al. Update on Systemic Prostate Cancer Therapies: Management of Metastatic Castration-resistant Prostate Cancer in the Era of Precision Oncology. Eur Urol 2019; 75: 88-99.

7. Tsao CK, Cutting E, Martin J, Oh WK. The role of cabazitaxel in the treatment of metastatic castration-resistant prostate cancer. Ther Adv Urol 2014; 6:97-104.

8. Rouyer M, Oudard S, Joly F, Fizazi K, Tubach F, Jove J, et al. Overall and progression-free survival with cabazitaxel in metastatic castration-resistant prostate cancer in routine clinical practice: the FUJ cohort. Br J Cancer 2019; 121: 1001-8.

9. Taylor BS, Schultz N, Hieronymus H, Gopalan A, Xiao Y, Carver BS, et al. Integrative genomic profiling of human prostate cancer. Cancer Cell 2010; 18: 11-22.

10. Bitting RL, Armstrong AJ. Targeting the PI3K/Akt/mTOR pathway in castration-resistant prostate cancer. Endocr Relat Cancer 2013; 20: R83-99.

11. Martini M, De Santis MC, Braccini L, Gulluni F, Hirsch E. PI3K/AKT signaling pathway and cancer: an updated review. Ann Med 2014; 46: 372-83.

12. Liu Z, Zhu G, Getzenberg RH, Veltri RW. The Upregulation of PI3K/ Akt and MAP Kinase Pathways is Associated with Resistance of Microtubule-Targeting Drugs in Prostate Cancer. J Cell Biochem 2015; 116: 1341-9.

13. Paller CJ, Antonarakis ES. Cabazitaxel: a novel second-line treatment for metastatic castration-resistant prostate cancer. Drug Des Devel Ther 2011; 5: 117-24.

14. Hongo H, Kosaka T, Oya M. Analysis of cabazitaxel-resistant mechanism in human castration-resistant prostate cancer. Cancer Sci 2018; 109: 2937-45.

15. Bumbaca B, Li W. Taxane resistance in castration-resistant prostate cancer: mechanisms and therapeutic strategies. Acta Pharm Sin B 2018; 8: 518-29.

16. Tannock IF, de Wit R, Berry WR, Horti J, Pluzanska A, Chi KN, et al. Docetaxel plus prednisone or mitoxantrone plus prednisone for advanced prostate cancer. N Engl J Med 2004; 351: 1502-12.

17. Petrylak DP, Tangen CM, Hussain MH, Lara PN Jr, Jones JA, Taplin $\mathrm{ME}$, et al. Docetaxel and estramustine compared with mitoxantrone and prednisone for advanced refractory prostate cancer. $\mathrm{N}$ Engl J Med 2004; 351: 1513-20.

18. Gottesman MM, Fojo $\mathrm{T}$, Bates SE. Multidrug resistance in cancer: role of ATP-dependent transporters. Nat Rev Cancer 2002; 2: 48-58.
19. Duran GE, Derdau V, Weitz D. Cabazitaxel is more active than first-generation taxanes in $\mathrm{ABCB} 1(+)$ cell lines due to its reduced affinity for P-glycoprotein. Cancer Chemother Pharmacol 2018; 81: 1095-103.

20. de Wit R, de Bono J, Sternberg CN, Fizazi K, Tombal B, Wülfing C, et al. Cabazitaxel versus Abiraterone or Enzalutamide in Metastatic Prostate Cancer. N Engl J Med 2019; 381: 2506-18.

21. Janku F, Yap TA, Meric-Bernstam F. Targeting the PI3K pathway in cancer: are we making headway? Nat Rev Clin Oncol 2018; 15: $273-$ 91.

22. Malik SN, Brattain M, Ghosh PM, Troyer DA, Prihoda T, Bedolla R, et al. Immunohistochemical demonstration of phospho-Akt in high Gleason grade prostate cancer. Clin Cancer Res 2002; 8: 1168-71.

23. Kosaka T, Miyajima A, Shirotake S, Suzuki E, Kikuchi E, Oya M. Longterm androgen ablation and docetaxel up-regulate phosphorylated Akt in castration resistant prostate cancer. J Urol 2011; 185: 2376-81.

24. Mulholland DJ, Tran LM, Li Y, Cai H, Morim A, Wang S. et al. Cell autonomous role of PTEN in regulating castration-resistant prostate cancer growth. Cancer Cell 2011; 19: 792-804.

25. Bhatnagar N, Li X, Padi SKR, Zhang Q, Thang M-S, Guo B. Downregulation of miR-205 and miR-31 confers resistance to chemotherapy-induced apoptosis in prostate cancer cells. Cell Death Dis 2010; 1: e105.

26. Hagman Z, Haflidadóttir BS, Ceder JA, Larne O, Bjartell A, Lilja H, et al. miR-205 negatively regulates the androgen receptor and is associated with adverse outcome of prostate cancer patients. $\mathrm{Br} \mathrm{J}$ Cancer 2003; 108: 1668-76.

27. Pashaei E, Pashaei E, Ahmady M, Ozen M, Aydin N. Meta-analysis of miRNA expression profiles for prostate cancer recurrence following radical prostatectomy. PLoS One 2017; 12: e0179543.

28. Kalhori MR, Irani S, Soleimani M, Arefian E, Kouhkan F. The effect of miR-579 on the PI3K/AKT pathway in human glioblastoma PTEN mutant cell lines. J Cell Biochem 2019; 120: 16760-74.

29. Zhang X, Shu L, Hosoi H, Murti KG, Houghton PJ. Predominant nuclear localization of mammalian target of rapamycin in normal and malignant cells in culture. J Biol Chem 2002; 277: 28127-34.

30. Tsang CK, Liu H, Zheng XF. mTOR binds to the promoters of RNA polymerase I- and III-transcribed genes. Cell Cycle 2010; 953-7.

31. Warner JR, Vilardell J, Sohn JH. Economics of ribosome biosynthesis. Cold Spring Harb Symp Quant Biol 2001; 66: 567-74. 